\title{
Г.В. Шония*
}

\section{НЕКОТОРЫЕ ПРОБЛЕМЫ СОВРЕМЕННОГО ТРУДОВОГО ПРАВА ФРАНЦИИ}

\begin{abstract}
Аннотация. В статье анализируется развитие современного трудового права Франции. Автор оценивает влияние концепций достойного труда МОт, качества труда и занятости EC. В статье рассматривается существующая правоприменительная практика и правовые гарантии работников Франции. В качестве нового вида гарантий выделяется новый вид договора о гарантиях обеспечения работой, анализируются особенности его применения для работников и работодателей. Также рассматривается закон по реализации трудовых прав стажеров и законодательные меры по устранению дискриминации в срере труда по гендерному признаку. В результате своего исследования автор приходит к выводу об усилении государственного вмешательства в трудовые отношения, увеличении гарантий для работников, ужесточении санкций для нарушителей трудового законодательства, реализации дополнительных мер по защите от дискриминации по гендерному признаку.

Ключевые слова: юриспруденция, трудовое право Франции, коллективный договор, правовые гарантии, антидискриминационное законодательство, трудовой договор, регулирование стажировок, массовое высвобождение, защита трудовых прав, принцип равенства в сфере оплаты труда.
\end{abstract}

$\square$ волюционное развитие современного трудового права Франции определяется прежде всего влиянием на него трех основных концепций - достойного труда МOT; качества труда и занятости EC; фрлексекьюрити, что приводит со всей неизбежностью к необходимости оптимизации правового регулирования коллективных увольнений; профессиональной подготовки; устранения дискриминации по признаку пола в сфрере заработной платы.

Модификация трудового права Франции видится в том, что сокращается объем договорного регулирования, а государство все более активно вмешивается в сореру регулирования процессов на рынке труда, что имеет большое позитивное значение и выражается в совершенствовании системы гарантий трудовых прав работников.

Проблема защиты прав работников, подлежащих сокращению по экономическим причинам, то есть по обстоятельствам, независящим от работников и связанных с деятельностью работодателя, а также безработ- ных, ставшими таковыми в результате коллективных увольнений, приобретает особую актуальность во Франции в последнее время о чем, в частности, свидетельствуют как изменения в трудовом законодательстве, так и в сфрере коллективно-договорного регулирования, которые связаны с введением особого вида договора- договора о гарантиях обеспечения работой (le Contrat de Sécurisation Professionnelle (CSP) $)^{1}$.

Подписав этот договор, лица, подлежащие сокращению по экономическим причинам, соглашаются активно искать работу, участвовать в программах профессиональной подготовки, а в качестве корреспондирующих этим обязанностям приобретают права, до-

В буквальном смысле данный правовой термин переводится как «договор профессиональной безопасности». Однако, на наш взгляд, в данном случае нужно использовать правила функционального метода. Иными словами, необходимо провести параллель с такой английской юридической дефиницией, как «job security», которая имеет уже устоявшийся перевод на русский язык как «обеспечение работой».

(C) Гури Вахтангович Шония

* Кандидат юридических наук, старший преподаватель кафедры трудового права и социального обеспечения Московского государственного юридического университета имени О.Е. Кутафина (МГЮА) [shoniyaguri@mail.ru]

123995, г. Москва, ул. Садовая-Кудринская, д. 9 
полнительные по сравнению с правами безработных, которые были уволены вследствие массового высвобождения, но которые не заключали подобного рода договоров.

Наличие данной правовой новации доказывает, что: во-первых, усиливается государственное регулирование на рынке труда, так как происходит усиление государственного воздействия на процессы, связанные с коллективными увольнениями; во-вторых, расширяется правовой статус лиц, подлежащих сокращению, посредством включения в него дополнительных трудовых прав и гарантий; в третьих, на работодателя и службу занятости возлагаются новые обязанности, реализация которых имеет своей целью способствовать как можно более эффеективной реинтеграции безработного в трудовую деятельность.

Основы создания новой системы гарантий для лиц, которые были уволены в связи с массовым высвобождением, закреплены в следующих актах: Закон Франции №2011893 от 28 июля 2011 г., ${ }^{2}$ Национальный межпрофессиональный коллективный договор от 31 мая $2011^{3}$,Коллективный договор ${ }^{4}$ от 19 июля 2011 г.

Договор о гарантиях обеспечения работой стал заключаться во Франции с 1 сентября 2011 г. в компаниях, где работают менее 1000 работников, или в случае ликвидации юридического лица и конкурсного управления. Кроме того, по общему правилу, требуется, как минимум год трудового стажа для лиц, которые выразили желание заключить подобного рода договор.

Основной целью договора является содействие процессу возвращения на постоянную работу безработных посредством профессиональной подготовки, переподготовки или оказания помощи для того, чтобы безработные занимались бизнесом.

Переподготовка и интеграция рассматриваются в тесной взаимосвязи с функционированием местных рынков труда, что, несомненно, способствует эффективности действия договоров о гарантиях обеспечения работой.

LOI $n^{\circ} 2011-893$ du 28 juillet 2011 pour le développement de l'alternance et la sécurisation des parcours professionnels. URL:http://www.legifrance.gouv.fr/affichTexte. do?cidTexte $=$ JORFTEXT000024408887\& categorieLien $=$ id (дата обращения:27.04.12).

Accord national interprofessionnel du 31 mai 2011 relatif au contrat de transition professionnelle URL:http:// www.lexisnexis.fr/pdf/DO/ANI_31mai2011_CSP.pd (дата обращения:27.04.12).

4 Convention du 19 juillet 2011 URL:http://www.unedic. org/documents/DIC/Juridique/Convention\%20CSP\%20 du\%2019\%2007\%2011.pdf (дата обращения: 27.04.12).
Данный договор заключается между трудоустраивающимся и Французским центром занятости (служба занятости) или Французской национальной ассоциацией профессионального образования для взрослых.

Работодатель обязан предложить каждому работнику, который подпадает под массовое высвобождение, договор о гарантиях обеспечения работой.

При этом должны соблюдаться условия, предусмотренные Трудовым кодексом Франции 5 (в редакции от 22 марта 2012 г.), который определяет момент, когда работодатель предлагает работнику, подлежащему сокращению по экономическим причинам, данный вид договора.

Так, в соответствии со ст. L1233-11 ТK Франции, работодатель, который намерен провести увольнение по экономическим причинам, будь-то индивидуальное увольнение или коллективное увольнение не менее десяти работников, в течение тридцати дней до принятия решения должен провести с данными работниками предварительное собеседование.

Вызов на подобное собеседование осуществляется посредством уведомления заказным письмом или уведомлением, которое вручается работнику лично под расписку. В этом уведомлении указывается тема встречи.

Предварительная встреча может состояться не менее чем за пять рабочих дней после уведомления заказным письмом или после непосредственной передачи письма работнику.

В свою очередь, в ст. L1233-28 TK Франции отмечается, что работодатель, который намерен провести коллективное увольнение по экономическим причинам по меньшей мере десяти работников, в течение тридцати дней, должен провести консультации с рабочим советом или представителями работников.

Следовательно, договор о гарантиях обеспечения работой предлагается работнику либо во время собеседования, либо во время консультаций с представителями работников.

Каждому работнику следует принять решение в течение 21 дня с момента получения предложения, согласен ли он с условиями договора о гарантиях обеспечения работой или выбирает традиционный путь получения пособия по безработице.

\footnotetext{
Code du travail. Доступ из правовой системы Франции «Legifrance».
} 
Для работника несомненна финансовая выгода заключения данного вида договора, так как в течение 12 месяцев он получает денежную сумму, составляющую $80 \%$ его прежнего заработка перед увольнением по экономическим причинам в данной организации.

Эта сумма также предоставляется сразу, в отличие от пособия по безработице, которое, как правило, выплачивается с задержкой.

Соглашение работника заключить такой договор предполагает прекращение трудового договора по взаимному согласию (по соглашению сторон) со своим работодателем.

Тем не менее в течение 12 месяцев за работником остается право подать иск в суд по поводу несправедливого увольнения по экономическим причинам. В любом случае работники, которые соглашаются на заключение договора о гарантиях обеспечения работой, имеют право на денежную компенсацию от своего работодателя в размере не менее той, которую они получил бы, если бы были уволены по экономическим соображениям, но без этого договора.

После заключения договора происходит оценка профессиональных навыков работника. Затем с учетом местного рынка труда и наличия вакантных рабочих мест, а также профессиональной ориентации безработного, для него составляется профессиональный план.

Кроме того, безработному предлагаются услуги по профессиональной подготовке и переподготовке, а также профессиональные консультации. На протяжение действия договора лицо, заключившее его, считается стажером в соответствии с французским законодательством. Помимо прочего, оно берет на себя обязательство активно искать работу, соблюдать меры, предусмотренные в договоре, и реагировать на предложения о работе. Два неоправданных отказа от предложения работы могут привести к прекращению договора о гарантиях обеспечения работой.

Влияние европейской концепции «качества труда и занятости» на развитие французского трудового законодательства также наиболее отчетливо проявляется и в области правового регулирования профессиональной подготовки и переподготовки, что прежде всего относиться к лицам, проходящим стажировку.

Изменения связаны с необходимостью усовершенствования системы гарантий трудовых прав, предоставляемых этим категориям лиц.

Наиболее ярким примером, доказывающим стремление французских органов власти вести работу по постоянному совершенствованию нормативных актов по данной проблеме, является принятие Закона «Шерпиона» (Loi Cherpion) от 28 июля 2011 г. ${ }^{6}$

Закон усиливает существующие меры, направленные на обеспечение реализации трудовых прав стажеров, а также вводит новые, которые создают более высокий уровень защиты трудовых прав , предусматриваемых для этих категорий граждан. Закон требует подписания трехстороннего договора (между работодателем, стажером и учебным заведением), ограничивает продолжительность стажировки, предусматривает ежемесячную оплату, определяет условия участия рабочих советов и устанавливает правила определения испытательного срока для последующей работы.

Таким образом, Закон от 28 июля 2011 вводит меры, направленные на укрепление правовой базы регулирования стажировок. Этот нормативный акт гласит, что стажировка должна осуществляться при соблюдении ряда условий:

1) трудовая деятельность стажера не может быть связана с решением задач, которые выполняет постоянный работник;

2) должен быть заключен трехсторонний договор, который подписывается работодателем, стажером и представителем учебного заведения;

3) стажировка должна предусматривать обучение лиц , которые должны быть интегрированы в программы подготовки специалистов.

Этот закон не распространяется на стажеров в возрасте до 16 лет и тех лиц, которые занимаются профессиональной подготовкой.

Кроме того, ограничивается продолжительность стажировки, проводимой в одной компании, до шести месяцев в течение учебного года.

Работодатели могут принять нового стажера на ту же должность, что и предыдущего, но после перерыва, эквивалентного 1/3 от продолжительности срока практики предыдущего стажера.

Соблюдение требования о перерыве не является обязательным в том случае, если предыдущий стажер решил оставить место стажировки по собственной инициативе.

Согласно новому закону, стажеры не имеют права на получение заработной платы, но

\footnotetext{
LOI n 2011-893 du 28 juillet 2011 pour le développement de l'alternance et la sécurisation des parcours professionnels. URL:http://www.legifrance.gouv.fr/affichTexte. do? cidTexte=JORFTEXT000024408887\& categorieLien= id (дата обращения: 27.04.12).
} 
им должна быть предоставлена премия от организации, если их стажировка имеет продолжительность более двух месяцев в том же учебном году. Сумма должна быть указана в договоре, подписанном стажером, учебным заведением и организацией.

Если стажировка длится менее двух месяцев, премия может быть предметом переговоров между сторонами, но это условие не является обязательным.

В организациях с численностью менее 300 работников в годовой отчет об экономической ситуации включаются сведения о числе стажеров и условия их занятости. В таких организациях рабочие советы имеют исключительное право на получение информации в течение каждого квартала о числе стажеров, условиях их работы и задачах, которые они выполняют.

Если организация решает нанять стажера в течение трех месяцев после окончания прохождения стажировки, время стажировки должно быть вычтено из испытательного срока. Вычитаемый период не может быть больше $50 \%$ продолжительности испытательного срока (за исключением случаев, когда предусматриваются более выгодные условия в соответствии с коллективным договором).

Реализация концепции достойного труда МОТ в трудовое законодательство Франции подразумевает в качестве одной из кардинальных целей устранение дискриминации в сорере труда по признаку пола, что прежде всего касается обеспечения равенства между мужчиной и женщиной в сфере оплаты труда, а именно в сорере ликвидации разрыва между оплатой труда мужчины и женщины.

Несомненно, что в данном случае со всей уверенностью можно говорить о наличии тенденции, имеющей уже более чем 10-летнюю историю, которая была инициирована Законом Франции от 9 мая 2001 г. «О равенстве женщин и мужчин в сфрере труда» ${ }^{7}$ (Loi $\mathrm{n}^{\circ}$ 2001-397 du 9 mai 2001 relative à l'égalité professionnelle entre les femmes et les hommes), который обязал руководство компаний вести переговоры с представителями работников по вопросу соблюдения гендерного равенства на рабочем месте.

В правовую базу андискриминационного законодательства Франции по данной проблеме входят также и следующие акты: За-

Loi n 2001-397 du 9 mai 2001 relative à l'égalité professionnelle entre les femmes et les homesURL:http://www. legifrance.gouv.fr/affichTexte.do?cidTexte=JORFTEXT0 $00000756495 \&$ fastPos $=2 \&$ fastReqId $=2129647834 \&$ cate gorieLien=cid\&oldAction=rechTexte (дата обращения: 27.04.12) кон Франции от 23 марта 2006 г. «О равенстве женщин и мужчин по вопросам заработной платы» (Loi n² 2006-340 du 23 mars 2006 relative à l'égalité salariale entre les femmes et les hommes) ${ }^{8}$; Закон Франции «О пенсионной реформе» от 9 ноября 2010 г. (LOI n 20101330 du 9 novembre 2010 portant réforme des retraites) $)^{9}$; Декрет « «О соблюдении принципа равенства в сорере труда между женщинами и мужчинами» от 7 июля 2011 г. (Décret $\mathrm{n}^{\circ}$ 2011-822 du 7 juillet 2011 relatif à la mise en œuvre des obligations des entreprises pour l'égalité professionnelle entre les femmes et les hommes) $)^{10}$.

Анализ данных нормативных актов позволяет сделать вывод об усилении государственного вмешательства в процесс правового регулирования трудовых отношений и прежде всего по вопросам обеспечения равенства между мужчинами и женщинами в сфере заработной платы.

Французские законы, хотя и содержали нормы, запрещающие дискриминацию по признаку пола, но не предусматривали систему мероприятий, которые бы обеспечили реализацию данного принципа. В настоящее время в нормативных актах Франции 2010-2012 гг. уже содержатся санкции за несоблюдение принципа равенства в сфрере оплаты труда.

Так, те французские компании, которые не предпринимают никаких действий, чтобы устранить разрыв в оплате труда между мужчинами и женщинами с помощью коллективного договора или одностороннего плана действий, могут быть оштрафованы на сумму до $1 \%$ от их расходов на заработную плату с 1 января 2012 г.

Предполагается, что санкции, предусмотренные новейшим фрранцузским антидискримнационным законодательством, должны исправить эту ситуацию. Это относится прежде всего к компаниям с численностью 50 и более работников, которые также должны будут ежегодно предоставлять доклад о сравнитель-

8 Loi n 2001-397 du 9 mai 2001 relative à l'égalité professionnelle entre les femmes et les hommes)URL:http:// www.legifrance.gouv.fr/affichTexte.do?cidTexte=JORFTE XT000000816849\& fastPos $=1 \&$ fastReqId $=1105393020 \& \mathrm{c}$ ategorieLien=cid\&oldAction=rechTexte (дата обращения: 27.04.12).

9 LOI n² 2010-1330 du 9 novembre 2010 portant réforme des retraites (дата обращения: 27.04.12).

10 Décret $\mathrm{n}^{\circ}$ 2011-822 du 7 juillet 2011 relatif à la mise en œuvre des obligations des entreprises pour l'égalité professionnelle entre les femmes et les homes. URL:http:// www.legifrance.gouv.fr/affichTexte.do?cidTexte=JORFT EXT000024326618\&dateTexte $=\&$ categorieLien $=\mathrm{id} \quad$ (дата обращения: 27.04.12). 
ном состоянии занятости и профессиональной подготовки для мужчин и женщин.

Кроме того, для борьбы с разницей в оплате труда по гендерному признаку руководство компаний, где трудится не менее 50 человек, теперь обязано предусматривать антидискриминационные мероприятия в коллективном договоре или составлять односторонний план действий обеспечения равенства посредством консультаций с представителями работников. Несоблюдение этих условий может привести к санкциям.

Последние изменения трудового законодательства Франции не только определяют содержание переговоров об устранении разрыва в заработной плате по гендерному признаку, но и обязывают руководство компаний определять цели в этой области, а также средства их достижения.
Для поддержки переговоров и составления плана действий компании должны составлять ежегодный доклад о сравнительном состоянии полной занятости и профессиональной подготовки для женщин и мужчин.

Таким образом, анализ трудового законодательства Франции позволяет сделать вывод о том, что оно находится в постоянном развитии. Этот процесс определяется потребностью во внедрении основных положений современных концепций трудового права, которые, несмотря на свои отличия, имеют одно общее- оптимизацию правового регулирования защиты трудовых прав работников, что наиболее отчетливо и прослеживается на основе последних изменений в трудовом праве Франции.

\section{Библиография:}

1. Киселев И.Я. Зарубежное трудовое право. М., 1999.

2. Киселев И.Я., Лушников А.М. Трудовое право России и зарубежных стран. Международные нормы труда: учебник / под ред. М.В. Лушниковой. Изд. 3-е, перераб. и доп. М.: Изд-во «Эксмо», 2008. 608 с.

3. Лютов Н.Л., Морозов П.Е. Международное трудовое право. М.: Проспект, 2011. 216 с.

\section{References (transliteration):}

1. Kiselev I.Ya. Zarubezhnoe trudovoe pravo. M., 1999.

2. Kiselev I.Ya., Lushnikov A.M. Trudovoe pravo Rossii i zarubezhnykh stran. Mezhdunarodnye normy truda: Uchebnik / pod red. M.V. Lushnikovoy. Izd. 3-e, pererab. i dop. M.: Izd-vo «Eksmo», 2008. 608 s..

3. Lyutov N.L., Morozov P.E. Mezhdunarodnoe trudovoe pravo. M.: Prospekt, 2011. 216 s. 